УДК 544.472:547.99

\title{
КИНЕТИКА НИЗКОТЕМПЕРАТУРНОГО ОКИСЛЕНИЯ ФЕРМЕНТАТИВНОГО ЛИГНИНА СОСНЫ (PINUS SILVESTRIS) В ВОДНО-ЩЕЛОЧНОЙ СРЕДЕ
}

\author{
(ㄷ) К.Л. Кайгородов, В.Е. Тарабанько*, М.Ю. Черняк, Ю.В. Челбина, Н.В. Тарабанько, М.А. Смирнова \\ Институт химии и химической технологии СО РАН, Федеральный \\ исследовательский центр «Красноярский научный центр СО РАН», \\ Академгородок, стр. 50/24, Красноярск, 660036 (Россия), e-mail: veta@icct.ru
}

Изучена кинетика окисления ферментативного лигнина сосны (бурая гниль) кислородом в водно-щелочной среде при 90-160 ${ }^{\circ} \mathrm{C}$. Показано, что выход ванилина монотонно растет с температурой в этом интервале от 3,4 до 5,6 мас. \% в расчете на лигнин. Наблюдаемая энергия активации процесса поглощения кислорода варьируется в зависимости от условий процесса в интервале 6-19 кДж/моль. Порядок процесса по давлению кислорода, рассчитанный по скоростям поглощения О2 в первые два часа окисления при $90-120^{\circ} \mathrm{C}$, имеет значение $1,02 \pm 0,05$. Низкое значение энергии активации процесса, а также первый порядок по кислороду указывают на диффузионный режим процесса в этих условиях. Полученные кинетические данные показывают, что с ростом глубины окисления лигнина возрастает роль процессов вырожденно-цепного разветвления в результате распада образующихся гидроперекисей. Волюмометрическим методом по выделению кислорода зарегистрирован распад гидроперекисей в процессе окисления в количестве более 16 мол \% в расчете на исходный лигнин. Рассмотрены основные причины и закономерности, определяющие монотонно возрастающую функцию зависимости селективности окисления лигнинов в ароматические альдегиды от температуры.

Ключевые слова: ванилин, ферментативный лигнин, кинетика, бурая гниль, Pinus silvestris, гидропероксиды, кислород.

Исследование выполнено при финансовой поддержке РФФИ, Правительства Красноярского края и Краевого фонда науки в рамках научного проекта № 16-43-242102.

\section{Введение}

Традиционные промышленные технологии химической переработки древесины дают весьма ограниченный ассортимент продуктов - целлюлозу, углеводы и этанол. Проблема переработки лигнина в ценные химические продукты привлекает внимание исследователей более 100 лет и в настоящее время обсуждается весьма активно [1-5]. Среди возможных направлений утилизации лигнинов следует отметить воз-

Кайгородов Константин Леонидович - младший научный сотрудник, e-mail: kulik@icct.ru

Тарабанько Валерий Евгеньевич - заведующий лабораторией комплексной переработки биомассы, доктор химических наук, профессор, старший научный сотрудник, e-mail: veta@icct.ru

Черняк Михаил Юрьевич - старший научный сотрудник, кандидат химических наук, e-mail: chem.krsk@gmail.com Челбина Юлия Вячеславовна - младший научный сотрудник, кандидат химических наук, e-mail: veta@icct.ru Тарабанько Николай Валерьевич - научный сотрудник, кандидат химических наук, e-mail: quartz8585@yandex.ru Смирнова Марина Александровна - младший научный сотрудник, кандидат химических наук, e-mail: veta@icct.ru можность их каталитического окисления кислородом в ароматические альдегиды: ванилин (4гидрокси-3-метоксибензальдегид) и сиреневый альдегид (4-гидрокси-3,5-диметоксибензальдегид) $[6,7]$. Они являются ценным и перспективным сырьем для фармацевтической, пищевой и парфюмерной промышленности [5, 8-10]. Получение ванилина окислением лигносульфонатов, отходов производства сульфитной целлюлозы, доминировало на мировом рынке в 50-70-х годах прошлого века и сохранилось в Скандинавии до настоящего времени [5].

\footnotetext{
* Автор, с которым следует вести переписку.
} 
Многие вопросы кинетики и механизма каталитического окисления лигнинов в щелочной среде можно в основном считать решенными [11-15], но заметны и некоторые «белые пятна». Одна из неизученных систематически закономерностей состоит во влиянии температуры на селективность окисления лигнинов в ароматические альдегиды.

Основной диапазон температур, в котором проводится окисление кислородом, совпадает с температурой нитробензольного окисления - $160-170{ }^{\circ} \mathrm{C}$. Это довольно высокая температура, обусловливающая высокое равновесное давление паров воды и, соответственно, рабочее давление процесса. Работ, прямо посвященных влиянию температуры на эффективность окисления лигнинов в ароматические альдегиды, в литературе нет, и ниже рассмотрены отрывочные сведения по этому вопросу.

В первую очередь отметим патент Шоффеля [16], в котором сообщается о возможности получения высоких выходов ванилина при окислении лигнинов при $200-220{ }^{\circ} \mathrm{C}$ : окисление кислородом без катализатора дает в этих условиях вдвое больше альдегида по сравнению с окислением при $160{ }^{\circ} \mathrm{C}$. Этот результат подтверждается данными $[17,18]$ : увеличение температуры некаталитического окисления осиновой древесины от 160 до 190-200 ㄷ приводит к практически двукратному повышению выходов ванилина и сиреневого альдегида (до 31 вес.\% в расчете на лигнин), что близко к лучшим результатам каталитического окисления осиновой древесины (табл. 1).

Таблица 1. Зависимость выходов ванилина и сиреневого альдегида при окислении осиновой древесины кислородом без катализатора в щелочной среде от температуры

\begin{tabular}{c|c|c}
\hline \multirow{2}{*}{ Температура, ${ }^{\circ} \mathrm{C}$} & \multicolumn{2}{|c}{ Выход, мас. \% от лигнина } \\
\cline { 2 - 3 } & Ванилин & Сиреневый альдегид \\
\hline 170 & 5,5 & 11,5 \\
180 & 7,4 & 15,6 \\
190 & 7,8 & 23,4 \\
200 & 7,8 & 19,7 \\
\hline
\end{tabular}

Увеличение температуры процесса каталитического окисления ферментативного лигнина осиновой древесины от 130 до $170{ }^{\circ} \mathrm{C}$ также приводит к росту выходов ванилина и сиреневого альдегида в два раза [19].

В процессе окисления нативного лигнина березовой древесины в интервале температур $160-190{ }^{\circ} \mathrm{C}$ максимальный выход ванилина и сиреневого альдегида достигается при 170 이.

Наблюдаемый рост выхода альдегидов при увеличении температуры [16-20] может быть обусловлен разными причинами, отметим две из них. С одной стороны, вполне очевидна термодинамическая тенденция: равновесие деполимеризации смещается вправо при увеличении температуры, и в некоторой степени это может объяснять наблюдаемую закономерность окислительного расщепления полимера на мономерные фрагменты. С другой стороны, можно отметить и следующую кинетическую закономерность следствие из возможного механизма образования ванилина [11]: димеризация феноксильных радикалов (уравнение (1)), дающая побочные продукты, может иметь близкую к нулю энергию активации, а окисление тех же радикалов (2)-(3) - значительно более высокий активационный барьер [21].

$$
\mathrm{Ar}-\dot{\mathrm{C}} \mathrm{HR}+\mathrm{Ar}-\dot{\mathrm{C}} \mathrm{HR}=\mathrm{Ar}-\mathrm{CHR}-\mathrm{CHR}-\mathrm{Ar}
$$

$$
\begin{gathered}
\mathrm{Ar}-\mathrm{C}^{\bullet} \mathrm{HR}+\mathrm{Cu}^{2+}=\mathrm{Ar}-\mathrm{C}^{+} \mathrm{HR}+\mathrm{Cu}^{+} \\
\mathrm{Ar}-\mathrm{C}^{+} \mathrm{HR}+\mathrm{OH}^{-}=\mathrm{Ar}-\mathrm{C}(\mathrm{OH}) \mathrm{HR}
\end{gathered}
$$

В результате увеличение температуры процесса приводит к росту вклада окисления феноксильных радикалов в целевые продукты и, соответственно, подавлению побочного маршрута димеризации (1).

Отметим также два фактора, которые могут действовать в противоположном направлении, т.е. повышать селективность процесса при снижении температуры. Энергия активации каталитического процесса ниже таковой для некаталитической реакции, и процесс в диффузионном режиме характеризуется 
меньшим значением наблюдаемой энергии активации по сравнению с кинетическим режимом. Эти элементарные соотношения приводят к росту вкладов каталитического процесса и кинетического режима при уменышении температуры. Следовательно, эти тенденции должны повышать селективность процессов по альдегидам при снижении температуры [11, 22]. В рамках рассмотренных выше экспериментальных результатов эти закономерности, однако, не проявляются. Тем не менее при окислении сульфатного лигнина в интервале температур $110-154{ }^{\circ} \mathrm{C}$ максимальный выход ванилина, 10,8 мас. \% на лигнин, получен при довольно низкой температуре $133{ }^{\circ} \mathrm{C}[23,24]$. Высокие выходы альдегидов и ацетопроизводных в расчете на лигнин получены в процессах кислородно-щелочной отбелки сосновой (17\%) и эвкалиптовой (19\%) технической целлюлозы при весьма низкой температуре $100{ }^{\circ} \mathrm{C}$ и высоком давлении кислорода 0,7 МПа [25]. Результат [25] уникален в смысле низкой температуры процесса и, по нашему мнению, требует дополнительной проверки.

В качестве одного из перспективных источников технологического сырья для получения ароматических альдегидов следует отметить ферментативные лигнины, отходы интенсивно исследуемых процессов ферментативного гидролиза древесины [19]. Их окисление, так же как и окисление лигнинов бурой гнили древесины [22], дает выходы ванилина, близкие к результатам окисления нативных лигнинов, что практически вдвое превышает эффективность окисления лигносульфонатов [5]. Лигнины бурой гнили рассеяны в природе и по этой причине не представляют интереса в качестве дешевого промышленного сырья. Однако они весьма удобны в качестве модельного объекта для изучения закономерностей окисления благодаря высокой растворимости в водно-щелочной среде, высоким выходам альдегидов и отсутствию кинетических затруднений, обусловленных связями нативного лигнина с углеводными компонентами древесины. Показано, что каталитическое окисление лигнина бурой гнили сосны при $160{ }^{\circ} \mathrm{C}$ дает до 18 масс. \% ванилина, что весьма близко к результатам окисления нативного лигнина [22].

Цель настоящей работы - изучение влияния температуры на кинетику и селективность окисления лигнина бурой гнили сосны (Pinus silvestris).

\section{Экспериментальная часть}

В работе использовали порошок ферментативного лигнина сосны (ФЛ, бурая гниль). Содержание целлюлозы в ФЛ, определенное азотно-спиртовым методом, составило 14,3 мас. \% в расчете на абсолютно сухое вещество, лигнина (сернокислотным методом) - 83,8 мас. \%, влажность - 3,4 мас. \%.

Реакционную массу готовили, последовательно добавляя в реактор при перемешивании для каталитического процесса: 400 мл воды, 15 г пентагидрата сульфата меди (II) $\left(\mathrm{CuSO}_{4} \times 5 \mathrm{H}_{2} \mathrm{O}\right), 45$ г $\mathrm{NaOH}$ и 20 г ФЛ; для некаталитического: 400 мл 2,5М раствора $\mathrm{NaOH}, 20$ г ФЛ.

Эксперименты проводили в автоклаве из нержавеющей стали объемом 1 л при температуре 90$140{ }^{\circ} \mathrm{C}$, термостатирование с точностью $\pm 2{ }^{\circ} \mathrm{C}$. Перемешивание осуществлялось с помощью магнитной мешалки (450-500 мин ${ }^{-1}$, диаметр автоклава 85 мм, якорь мешалки диаметром 10 мм и длиной 60 мм, критерий Рейнольдса, рассчитанный для чистой воды, $\mathrm{Re}=1,2-2,0 \times 10^{5}$ ).

Кислород в реактор подавали из калиброванной буферной емкости через специальный вентиль по мере поглощения реакционной массой, поддерживая постоянное давление. Количество поглощенного кислорода измеряли по снижению давления в буферной емкости. Скорость поглощения определяли измерением количества кислорода, поглощенного за определенный интервал времени.

В экспериментах для оценки влияния гидроперекисей на кинетику окисления в пределах одного эксперимента и на одном образце лигнина парциальное давление кислорода изменяли ступенчато в прямом и обратном направлении по 0,2 МПа в диапазоне от 0,1 до 1,5 МПа через каждые 15 мин. Скорость поглощения кислорода на каждой ступени регистрировали, начиная с момента вывода системы на рабочее давление в течение 3-6 мин. На участках снижения давления в течение первых 1-3 мин после сброса давления наблюдался его рост в результате выделения кислорода из раствора и испарения воды. Прирост давления фиксировали и сбрасывали кислород из реактора до требуемого рабочего давления. Наблюдаемый прирост давления в реакторе достигал величин вплоть до 200 кПа.

Через определенные промежутки времени отбирали пробы реакционной массы. Полученные пробы объемом 13-15 мл доводили раствором $1 \mathrm{M} \mathrm{HCl}$ до рН 3-4 и исчерпывающе экстрагировали хлороформом. 
Концентрацию альдегидов определяли методом ГЖХ (колонка 25 м × 0,22 мм × 1,0 мкм SE-30). Температура термостата колонки $170{ }^{\circ} \mathrm{C}$. Внутренний стандарт - антрацен.

\section{Результаты и обсуждение}

На рисунке 1 представлены результаты окисления ферментативного лигнина сосны при $110^{\circ} \mathrm{C}$ и давлении кислорода 1,5 МПа. Катализатор увеличивает выход ванилина в этом эксперименте почти в два раза - в расчете на загруженный лигнин выход возрастает с 3,0 до 5,4 масс. \%. Ранее аналогичный рост скорости наблюдался при окислении лигносульфонатов при этой температуре [12]. На рисунке 2 представлены данные по влиянию температуры процесса на динамику и выходы ванилина. Полученные результаты показывают, что в интервале $90-160{ }^{\circ} \mathrm{C}$ максимальные выходы ванилина монотонно убывают при понижении температуры.

Для прояснения деталей низкотемпературного окисления более детально изучена кинетика поглощения кислорода в процессе окисления ферментативного лигнина без катализатора. На рисунке 3 представлены зависимости скорости поглощения кислорода от его давления, изменяемого ступенями на одной загрузке реакционной массы. Сплошная кривая описывает изменение скорости при повышении давления от 0,1 до 1,5 МПа и далее - при его снижении до первоначального значения 0,1 МПа. Пунктирная кривая описывает аналогичную зависимость, полученную в противоположном направлении, при снижении давления и последующем его увеличении в том же диапазоне. Обе линии имеют отчетливый гистерезис, но близки друг к другу.

Полученные кривые воспроизводятся (рис. 4) и имеют отчетливый гистерезис: начальная половина линии (линия роста давления) располагается ниже ее конечной части (линия снижения давления). Различия скоростей на ветвях подъема и снижения давления сокращаются при увеличении температуры (рис. 4). Такой гистерезис трудно объяснить возрастающей глубиной окисления лигнина, и более убедительно предположение о накоплении гидроперекисей в процессе окисления лигнина кислородом. Накопление гидроперекисей в реакционной массе в ходе процесса должно увеличивать скорость инициирования за счет их распада (механизм вырожденного разветвления цепей) и, следовательно, скорость процесса в целом [15]. В результате скорость процесса при заданном давлении кислорода оказывается выше на второй части кривой, где гидроперекиси уже накоплены в результате окисления при высоких давлениях, по сравнению с первой, начальной половиной.

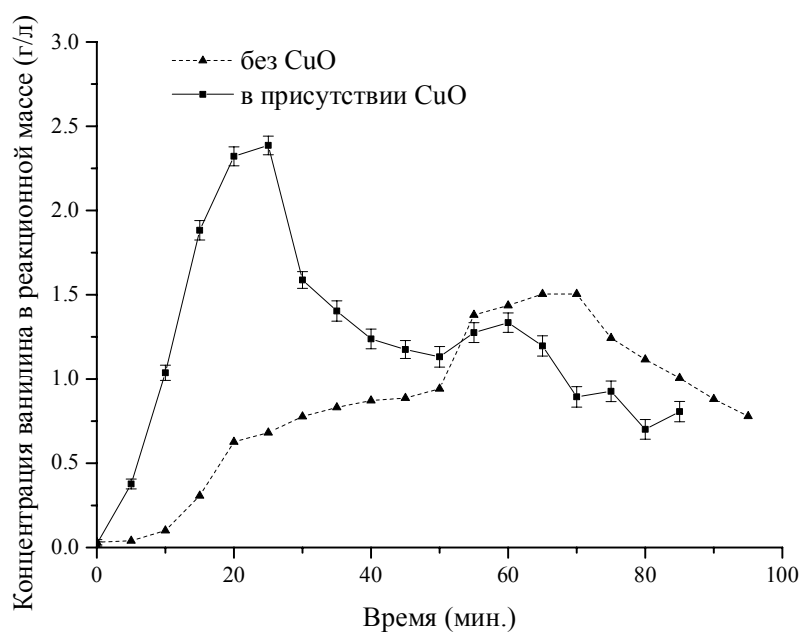

Рис. 1. Динамика накопления ванилина при окислении ферментативного лигнина сосны (ФЛ) в щелочной среде в присутствии оксида меди (II) и без него при постоянном давлении кислорода 1,5 МПа и $110^{\circ} \mathrm{C}$

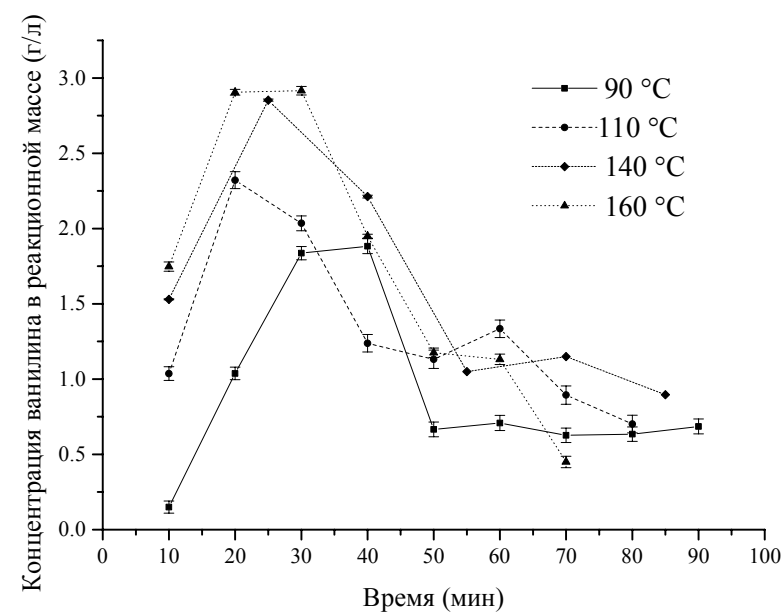

Рис. 2. Динамика накопления ванилина при окислении ферментативного лигнина сосны (ФЛ) в щелочной среде в присутствии оксида меди (II) при давлении кислорода 0,2 МПа и температурах $90-160{ }^{\circ} \mathrm{C}$ 


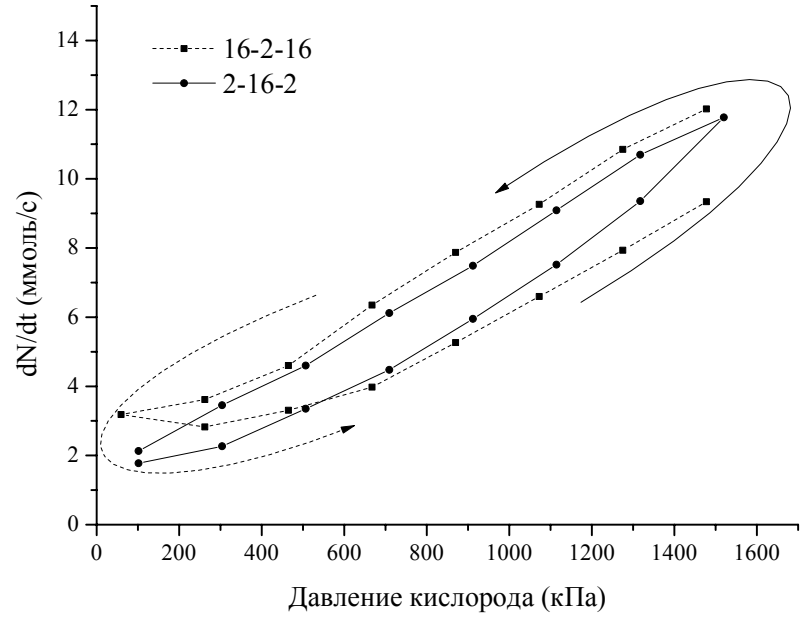

Рис. 3. Зависимости скорости поглощения кислорода при окислении бурой гнили сосны в щелочной среде от давления при ступенчатом увеличении и снижении давления кислорода от 0,1 до 1,5 МПа, 90 $\mathrm{C}$, продолжительность экспериментов - 3 ч

Рис. 5. Зависимость количества выделяющихся из жидкой фазы в реактор газов от давления кислорода после его снижения при окислении ферментативного лигнина сосны в щелочной среде при $110^{\circ} \mathrm{C}$

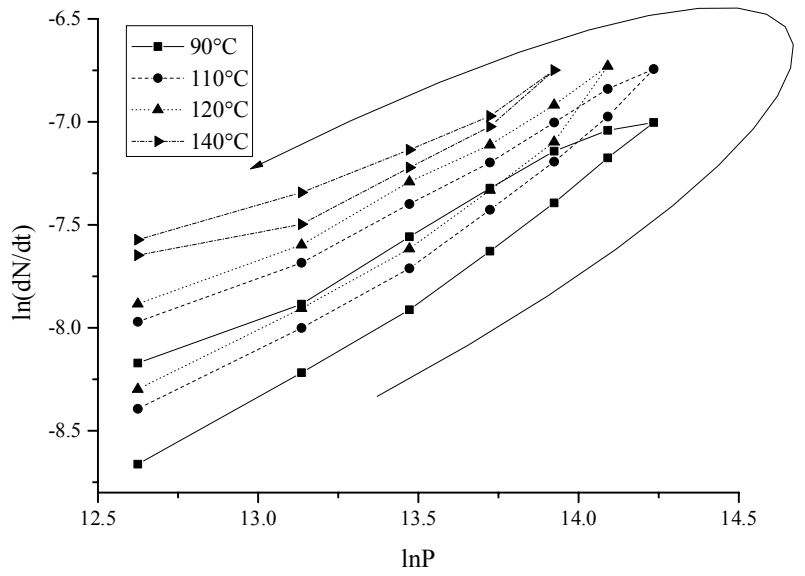

Рис. 4. Логарифмические зависимости скорости поглощения кислорода при окислении бурой гнили сосны в щелочной среде от давления при ступенчатом увеличении и снижении давления кислорода от 0,1 до 1,5 МПа в интервале температур 90-140 ㄷ, продолжительность экспериментов - 3 ч, интервал между экспериментальными точками - 15 мин. Стрелкой указана последовательность экспериментальных точек во времени

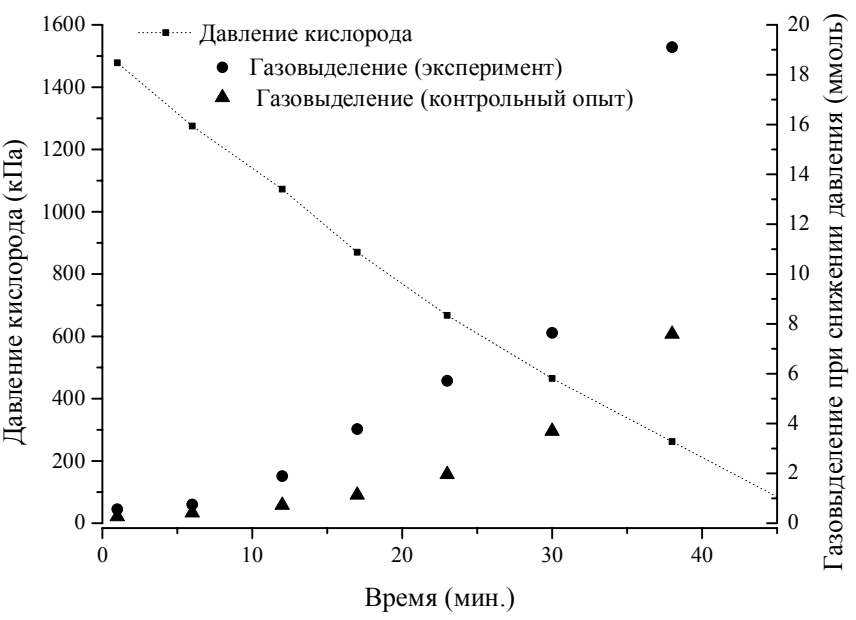

Накопление гидроперекисей в реакционной массе подтверждается прямым наблюдением роста давления в реакторе после сброса кислорода до необходимого давления в ходе процесса на участке снижения давления (рис. 5). После сброса газа в атмосферу давление в реакторе нарастает в течение 5-6 мин, и его максимальный прирост, пересчитанный в количество выделившихся газов, достигает 19 ммоль при минимальных температуре и давлении процесса. В холостом эксперименте без лигнина аналогичный прирост давления после его снижения примерно вдвое меньше и соответствует 8 ммоль газа. Этот прирост, очевидно, обусловлен испарением воды после сброса паров и кислорода из реактора, а также выделением растворенного кислорода из жидкой фазы в газовую в результате снижения его парциального давления. Разность объемов газов (до 11 ммоль), выделившихся в эксперименте по окислению лигнина и в контрольном опыте, обусловлена химическими процессами выделения кислорода, т.е. распадом гидроперекисей. Стехиометрия распада гидроперекисей соответствует выделению максимум 0,5 моль кислорода на моль гидроперекиси, следовательно, количество распадающихся гидропероксидов достигает 22 ммоль (рис. 5). Количество лигнина в реакторе в пересчете на фенилпропановую единицу (121 а.е.м.) составляет около 140 ммоль, т.е. текущая концентрация гидроперекисей в ходе окисления может превышать значения, соответствующие 16 мол. \% в расчете на исходный лигнин. 
Высокая скорость разложения гидроперекисей обусловливает относительно низкие скорости окисления на второй половине линии (подъем давления) по сравнению с первой половиной линии снижения давления (рис. 3). При изменении давления в системе в этом направлении (сверху вниз и далее вверх) к началу второго участка расходуется и лигнин, и гидроперекиси, и скорости окисления на этом участке оказываются ниже по сравнению со скоростями на первой части линии при равных давлениях кислорода.

В таблице 2 приведены скорости окисления в зависимости от давления и температуры процесса. В интервале 0,3-1,5 МПа на ветви подъема давления порядок процесса по давлению кислорода при $90-120^{\circ} \mathrm{C}$ имеет значение $1,02 \pm 0,05$ и снижается до 0,68 при $140{ }^{\circ} \mathrm{C}$. Первый порядок реакции по кислороду может указывать на диффузионный режим протекания процесса. Низкое расчетное значение энергии активации (619 кДж/моль) также указывает на диффузионный характер окисления лигнина в рассматриваемых условиях.

Наблюдаемая энергия активации систематически снижается с ростом давления кислорода. Это указывает на рост диффузионного торможения процесса при увеличении $\mathrm{P}_{\mathrm{O}_{2}}$ и, следовательно, на порядок процесса по кислороду меньше единицы в кинетическом режиме.

Порядок по кислороду меньше единицы получен на втором участке процесса (135-210 мин). Это может быть обусловлено глубокой степенью окисления лигнина на этом участке, соответствующим снижением скорости окисления и, следовательно, смещением режима процесса в область кинетического контроля.

Таблица 2. Зависимость кинетических параметров поглощения кислорода от его давления и температуры в процессе окисления ферментативного лигнина сосны

\begin{tabular}{|c|c|c|c|c|c|c|}
\hline \multirow{2}{*}{$\mathrm{P}\left(\mathrm{O}_{2}\right)$, атм. } & \multirow{2}{*}{$\begin{array}{c}\text { Продолжительность } \\
\text { процесса, мин }\end{array}$} & \multicolumn{4}{|c|}{$\mathrm{dn}\left(\mathrm{O}_{2}\right) / \mathrm{dt}, 10^{-4}$ моль/сек при температуре, ${ }^{\circ} \mathrm{C}$} & \multirow{2}{*}{$\begin{array}{c}\text { Энергия активации, } \\
\text { кДж/моль }\end{array}$} \\
\hline & & 90 & 110 & 120 & 140 & \\
\hline 3 & 30 & 1,73 & 2,26 & 2,49 & 4,77 & 18,8 \\
\hline 5 & 45 & 2,70 & 3,35 & 3,69 & 5,55 & 13,7 \\
\hline 7 & 60 & 3,66 & 4,48 & 4,92 & 7,30 & 13,1 \\
\hline 9 & 75 & 4,87 & 5,95 & 6,54 & 8,91 & 11,6 \\
\hline 11 & 90 & 6,15 & 7,52 & 8,27 & 11,72 & 12,4 \\
\hline 13 & 105 & 7,65 & 9,35 & 11,95 & - & 11,8 \\
\hline 15 & 120 & 9,09 & 11,78 & - & - & 10,8 \\
\hline $\begin{array}{c}\text { Порядок } \\
\text { по кислороду }\end{array}$ & & 1,03 & 1,02 & 1,02 & 0,68 & \\
\hline 13 & 135 & 8,75 & 10,70 & - & - & 8,4 \\
\hline 11 & 150 & 7,91 & 9,09 & 9,90 & - & 6,2 \\
\hline 9 & 165 & 6,60 & 7,49 & 8,15 & 9,38 & 7,1 \\
\hline 7 & 180 & 5,22 & 6,12 & 6,82 & 7,96 & 8,6 \\
\hline 5 & 195 & 3,76 & 4,60 & 5,02 & 6,47 & 10,1 \\
\hline 3 & 210 & 2,83 & 3,45 & 3,77 & 5,15 & 11,6 \\
\hline $\begin{array}{c}\text { Порядок } \\
\text { по кислороду }\end{array}$ & & 0,80 & 0,76 & 0,72 & 0,51 & \\
\hline
\end{tabular}

\section{Заключение}

Рассмотренные результаты показывают, что окисление ферментативного лигнина сосны при 90$160{ }^{\circ} \mathrm{C}$ в условиях массообмена, характерных для технологических реакторов (число Рейнольдса порядка $10^{5}$ ), протекает в диффузионном режиме. На диффузионный режим процесса указывают низкое значение энергии активации процесса (6-19 кДж/моль) и первый порядок по давлению кислорода.

Волюмометрическим методом обнаружено разложение гидропероксидов в процессе окисления лигнина, и их текущая концентрация в ходе окисления может превышать значения, соответствующие 16 мол. \% в расчете на исходный лигнин. Образование гидроперекисей при окислении лигнина - побочный процесс с точки зрения механизма образования ванилина [11], и при низкой температуре он может ограничивать выход ванилина. Катализатор (оксид меди) увеличивает скорость поглощения кислорода и выход ванилина в два раза по сравнению с некаталитическим процессом.

В интервале $90-160{ }^{\circ} \mathrm{C}$ максимальные выходы ванилина монотонно убывают при понижении температуры. Эти результаты в совокупности с данными $[11,16,17,22]$ показывают, что доминирующая закономерность, связывающая температуру процесса окисления лигнинов и выход ванилина, заключается в росте селективности процесса при увеличении температуры его проведения в интервале $110-190{ }^{\circ} \mathrm{C}$. Отметим две возможные причины такой закономерности. Во-первых, образующиеся при окислении в качестве интермедиатов феноксильные радикалы могут расходоваться по двум маршрутам: димеризация в по- 
бочные продукты, протекающая с близкой к нулю энергией активации, и окисление тех же радикалов в целевые вещества (со значительно более высоким активационным барьером [21]). Это соотношение приводит к росту вклада второго маршрута при увеличении температуры. Во-вторых, вполне очевидна термодинамическая тенденция: равновесия деполимеризации смещаются вправо при увеличении температуры, и в некоторой степени это может объяснять наблюдаемую закономерность окислительного расщепления полимера на мономерные фрагменты.

\section{Список литературы}

1. Чудаков М.И. Промышленное использование лигнина. М., 1983. 212 с.

2. Zakzeski J., Bruijnincx P.C.A., Jongerius A.L., Weckhuysen B.M. The catalytic valorization of lignin for the production of renewable chemicals // Chemical Reviews. 2010. Vol. 110, iss. 6. Pp. 3552-3599.

3. Pandey M.P., Kim. C.S. Lignin Depolymerization and Conversion: A Review of Thermochemical Methods [Review] // Chemical Engineering \& Technology. 2011. Vol. 34, iss. 1. Pp. 29-41.

4. Li C.Z., Zhao X.C., Wang A.Q. Huber G.W., Zhang T. Catalytic Transformation of Lignin for the Production of Chemicals and Fuels // Chemical Reviews. 2015. Vol. 115, iss. 21. Pp. 11559-11624.

5. Encyclopedia of chemical technology. 2nd Ed., ed. H.V. Mark. Interscience Publ., J.W.\& Sons. N.-Y.; London, 1972. Vol. 21. Pp. 180-196.

6. Грушников О.П., Елкин В.В. Достижения и проблемы химии лигнина. М., 1973. 189 с.

7. Гоготов А.Ф. Анализ сырьевой базы для получения ароматических альдегидов // Химия растительного сырья. 1999. №2. C. 73-79.

8. Szallasi A., Blumberg P.M. Mechanisms and terapeutic potentials of vanilloids (capsaicin-like molecules) // Adv. Pharmacol. San-Diego. 1993. Vol. 24. Pp. 123-155.

9. MacRae W.D., Towers G.H.N. Biological activities of lignans // Phytochemistry. 1984. Vol. 23. Pp. 1207-1220.

10. Ерофеев Ю.В., Афанасьева В.Л., Глушков Р.Г. Способы получения 3,4,5-триметоксибензальдегида // Химикофармацевтический журнал. 1990. Вып. 7. С. 50-56.

11. Тарабанько В.Е., Петухов Д.В., Селютин Г.Е. Новый механизм каталитического окисления лигнина в ванилин // Кинетика и катализ. 2004. Т. 45, №4. С. 603-611.

12. Taraban'ko V.E., Fomova N.A., Kuznetsov B.N., Kudryashev A.V., Ivanchenko N.M. On the mechanism of vanillin formation in catalytic oxidation of lignin with oxygen. // React. Kinet. Catal. Lett. 1995. Vol. 55, N1. Pp. 161-170.

13. Tarabanko V.E., Pervishina E.P., Hendogina Yu.V. Kinetics of aspen wood oxidation by oxygen in alkaline media // React. Kinet. Catal. Lett. 2001. Vol. 72, N1. Pp. 153-162.

14. Тарабанько В.Е., Первышина Е.П., Невкрытова Т.А., Пен Р.З. Исследование кинетики процесса окисления осиновой древесины кислородом в щелочной среде // Химия растительного сырья. 1999. №4. С. 53-59.

15. Tarabanko V.E., Pervishina E.P., Tarabanko N.V., Chernyak M.Yu., Kaygorodov K.L., Chelbina Yu.V., Boyarchuk D.V. Kinetics of fir wood oxidation by oxygen in aqueous alkaline media // Химия растительного сырья. 2016. №4. С. 57-63.

16. Патент 2598311 (US). Manufacture of vanillin / E.W. Schoefel. 1952.

17. Первышина Е.П. Исследование кинетики и разработка новых методов окисления лигнина древесины осины и пихты молекулярным кислородом в водно-щелочной среде: дисс. ... канд. хим. наук. Красноярск, 2000. 120 с.

18. Патент 2178405 (РФ). Способ переработки древесины мелколиственных пород / В.Е. Тарабанько, Е.П. Первышина, Б.Н. Кузнецов. 2002.

19. Тарабанько В.Е., Кайгородов К.Л., Коропачинская Н.В., Челбина Ю.В., Ильин А.А. Получение ароматических альдегидов из отходов производства биобутанола // Химия в интересах устойчивого развития. 2012. T. 20. C. $471-476$.

20. Коропачинская Н.В., Тарабанько В.Е., Черняк М.Ю. Каталитическое окисление березовой древесины (Вetula Pendula Roth.) кислородом в сиреневый альдегид и ванилин // Химия растительного сырья. 2003. №2. С. 9-14.

21. Денисов Е.Т. Константы скорости гомолитических жидкофазных реакций. М., 1971. 712 с.

22. Тарабанько В.Е., Коропачинская Н.В., Кудряшев А.В., Кузнецов Б.Н. Влияние природы лигнина на эффективность каталитического окисления в ванилин и сиреневый альдегид // Известия Академии наук. Сер. хим. 1995. Вып. 2. С. 375-379.

23. Fargues C., Mathias A., Rodrigues A. Kinetics of vanillin production from kraft lignin oxidation // Ind. Eng. Chem. Res. 1996. Vol. 35, N1. Pp. 28-36.

24. Pinto P.C.R., Borges da Silva E.A., Rodrigues A.E. Insights into Oxidative Conversion of Lignin to High-AddedValue Phenolic Aldehydes // Ind. Eng. Chem. Res. 2011. Vol. 50, N2. Pp. 741-748.

25. Wong Z.J., Chen K.F., Li J. Formation of vanillin and syringaldehyde in an oxygen delignification process // Bioresources. 2010. Vol. 5, iss. 3. Pp. 1509-1516. 
Kaygorodov K.L., Tarabanko V.E., Chernyak M.Yu., Chelbina Yu.V., Tarabanko N.V., Smirnova M.A. LOWTEMPERATURE KINETICS OF ENZYMATIC PINE (PINUS SILVESTRIS) WOOD LIGNIN OXIDATION IN THE ALKALINE MEDIA

Institute of Chemistry and Chemical Technology SB RAS, Federal Research Center "Krasnoyarsk Science Center SB RAS”, Akademgorodok, 50/24, 660036, Krasnoyarsk (Russia), e-mail: veta@icct.ru

Kinetics of the enzymatic lignin (brown rotted wood) of pine wood (Pinus silvestris) by oxygen in water-alkaline media at $90-160^{\circ} \mathrm{C}$ is studied. The vanillin yield in the process increases from 3 to $5,6 \mathrm{wt} \%$ based on the lignin when increasing the temperature on the shown interval. Calculated value of the observed activation energy varies in the interval 6-19 kJ/mol depending of the experimental conditions. The reaction order with respect to the oxygen pressure was calculated, and it was equal to $1,02 \pm 0,05$ in the interval of the first two hours of the process. Low value of the process activation energy and the determined value of the reaction order, both these data demonstrate diffusion field of studied kinetics of the process. The obtained kinetic results show that during the oxidation process the role of the degenerated brunch chain process increases due to the formed hydroperoxides destruction. The oxygen emission from water phase as a result of hydroperoxides destruction was registered by volumetric method. A volume of oxygen gas formed corresponds to the hydroperoxides destruction of 16 mol $\%$ based on the initial lignin. The increasing function of the temperature dependence of the selectivity process is discussed and explained.

Keywords: vanillin, enzymatic lignin, kinetics, brown rotted wood, Pinus silvestris, hydroperoxides, oxygen.

\section{References}

1. Chudakov M.I. Promyshlennoe ispolzovanie lignina [Industrial use of lignin]. Moscow, 1983, 212 p. (in Russ.).

2. Zakzeski J., Bruijnincx P.C.A., Jongerius A.L., Weckhuysen B.M. Chemical Reviews, 2010, vol. 110, iss. 6, pp. 3552-3599.

3. Pandey M.P., Kim. C.S. Chemical Engineering \& Technology, 2011, vol. 34, iss. 1, pp. 29-41.

4. Li C.Z., Zhao X.C., Wang A.Q. Huber G.W., Zhang T. Chemical Reviews, 2015, vol. 115, iss. 21, pp. 11559-11624.

5. Mark H.V. Encyclopedia of chemical technology. 2nd Ed. Interscience Publ., J.W.\& Sons. N.-Y. ; London, 1972, vol. 21, pp. 180-196.

6. Grushnikov O.P, Elkin V.V. Dostizheniya i problemy khimii lignina [Achievements and problems in chemistry of lignin]. Moscow, 1973, 189 p. (in Russ.).

7. Gogotov A.F. Khimiia rastitel'nogo syr'ia, 1999, no. 2, pp. 73-79. (in Russ.).

8. Szallasi A., Blumberg P.M. Adv. Pharmacol, 1993, vol. 24, pp. 123-155.

9. MacRae W.D., Towers G.H.N. Phytochemistry, 1984, vol. 23, pp. 1207-1220.

10. Erofeev Yu.V., Afanas'eva V.L., Glushkov R.G. Khimiko-Farmatsevticheskii Zhurnal, 1990, vol. 24, no. 7, pp. 5056. (in Russ.).

11. Tarabanko V.E., Petukhov D.V., Selyutin G.E. Kinetics and Catalysis, 2004, vol. 45, no. 4, pp. 603-611. (in Russ.).

12. Tarabanko V.E., Fomova N.A., Kuznetsov, B.N., Kudryashev A.V., Ivanchenko N.M. React. Kinet. Catal. Lett, 1995, vol. 55, no. 1, pp. 161-170.

13. Tarabanko V.E., Pervishina E.P., Hendogina Yu.V. React. Kinet. Catal. Lett, 2001, vol. 72, no. 1, pp. 153-162.

14. Tarabanko V.E., Pervishina E.P., Nevkrytova T.A., Pen R.Z. Khimiia rastitel'nogo syr'ia, 1999, no. 4, pp. 53-59. (in Russ.).

15. Tarabanko V.E., Pervishina E.P., Tarabanko N.V., Chernyak M.Yu., Kaygorodov K.L., Chelbina Yu.V., Boyarchuk D.V. Khimiia rastitel'nogo syr'ia, 2016, no. 4, pp. 57-63. (in Russ.).

16. Patent 2598311 (US). 1952.

17. Pervishina E.P. Issledovanie kinetiki I razrabotka novyh metodov okislenia lignina drevesiny osiny i pihty molekulyarnim kislorodom v vodno-shelochnoi srede : diss. kand. chim. nauk. [Research of kinetics and development of new methods of lignin oxidation of aspen and fir wood by molecular oxygen in water-alkaline environment: the dissertation of the candidate of chemical sciences.]. Krasnoyarsk, 2000, 120 p. (In Russ.).

18. Patent 2178405 (RU). 2002. (in Russ.).

19. Tarabanko V.E., Kaigorodov K.L., Koropachinskaya N.V., Chelbina Yu. V., Il'in A.A. Khimiia rastitel'nogo syr'ia, 2012, Vol. 20, pp. 471-476. (in Russ.).

20. Koropachinskaya N.V., Tarabanko V.E., Chernyak M.Yu. Khimiia rastitel'nogo syr'ia, 2003, vol. 2, pp. 9-14. (in Russ.).

21. Denisov E.T. Konstanty skorosti gomoliticheskih zhidkofaznih reakcii [Liquid-Phase Reaction Rate Constants]. Moscow, 1971, 712 p. (in Russ.).

22. Tarabanko V.E., Koropachinskaya N.V., Kudryashev A.V., Kuznezov B.N. Izvestiya Akademii nauk, seriya khimiya [Russian Chemical Bulletin], 1995, vol. 2, pp. 375-379. (In Russ.).

23. Fargues C., Mathias A., Rodrigues A. Ind. Eng. Chem. Res, 1996, vol. 35, no. 1, pp. 28-36.

24. Pinto P.C.R., Borges da Silva E.A., Rodrigues A.E. Ind. Eng. Chem. Res, 2011, vol. 50, no. 2, pp. 741-748.

25. Wong Z.J., Chen K.F., Li J. Bioresources, 2010, vol. 5, iss. 3, pp. 1509-1516.

\footnotetext{
${ }^{*}$ Corresponding author.
} 